\title{
Saliva - A New Horizon for Estimating Antioxidant Profile of Mobile Phone User
}

\author{
Asra Khan ${ }^{1}$, Suad Naheed ${ }^{2, *}$, Mehtab Alam ${ }^{3}$, Saba Salahuddin ${ }^{1}$ \\ 1Department of Biochemistry, Jinnah University for Women, Karachi 74600, Pakistan \\ 2Department of Biotechnology, Jinnah University for Women, Karachi 74600, Pakistan \\ 3Department of Biochemistry, Dow International Medical College, Dow University of Health Sciences, Ojha Campus, \\ Karachi, Pakistan
}

\section{ABSTRACT}

This is the era of information and new technologies, among the brilliant inventions and advancement, Global system of mobile phone communication (GSM) makes the life as approachable as one can think. It changes the social relation and social network of an individual. Hence the mobile has two sides of a coin. Advantages and disadvantages are associated with every feasibility or inventions. But some time blessings bring some harmful effects on the human body. Mobile phone uses radio waves. Some part of the radio wave is also absorbed in the body. The ear is the most exposed part of the body. The salivary gland is very close to the ear. Hence, the affected part of the cellular phone radiations is a salivary gland.

In the current study, we collected the unstimulated saliva sample from volunteers to estimate the antioxidant profile of the mobile phone user. The Uric acids, Catalase, C Reactive Protein (CRP), Reduced Glutathione (GSH), and Superoxide Dismutase (SOD) were included in the antioxidant profile. Uric acid, GSH, SOD was significantly decreased while CRP and Catalase were significantly increased. The result shows the increase the risk of inflammation and oxidative stress, which can predispose the cell phone user to a multitude of infectious \& non-infectious oral diseases.

$\begin{array}{lll}\text { Keywords } & \text { *Address of Correspondence } & \text { Article info. } \\ \begin{array}{l}\text { Saliva, mobile phone, antioxidant profile, } \\ \text { oxidative stress, oral disease. }\end{array} & \text { suadnaheed@yahoo.com } & \text { Received: August 13, 2018 } \\ \text { Accepted: January 8, 2019 }\end{array}$

Cite this article: Khan A, Naheed S, Alam M, Salahuddin S. Saliva - A New Horizon for Estimating Antioxidant Profile of Mobile Phone User. RADS J. Biol. Res. Appl. Sci. 2019; 10(1):

Funding Source: Nil Conflict of Interest: Nil 23-29.

This is an Open Access article distributed under the terms of the Creative Commons Attribution License (http://creativecommons.org/licenses/by/4.0), which permits unrestricted use, distribution, and reproduction in any medium, provided the original work is properly cited.

\section{INTRODUCTION}

The $21^{\text {st }}$ century is the century of technology; in this era, vast technologies are present around us that make human life as much comfortable as possible. Among the brilliant inventions and advancements, cellular phones have made life as much approachable as one can think. Mobile phones in present days have become a habit for each and every person. It shortens the distance; people get closer to each other. These devices use electromagnetic radiations, thereby producing possible harmful effects on the human body. Advantages and disadvantages are associated with every facility or invention. Global System of Mobile Communication
(GSM) may play an important role in medical aspects or healthcare management; as they are associated with various ill effects ${ }^{1}$. Mobile phones, being wireless communication devices use electromagnetic radiations of microwaves (Radiofrequency ranges from $300 \mathrm{MHz}$ to $300 \mathrm{GHz}$ ). Technically, when you are speaking on phone, your sound wave is converted into a sine wave by using a transmitter. This transmitter uses the power of the highest 1 from shortest 0.75 Watt, with $2 \mathrm{~W}$ at hit the highest point. The antenna catches the signal from the transmitter and spreads it in all directions. The current of electric sine wave makes electromagnetic fields around the 
transmitter. The electromagnetic radiations are formed by collapse and buildup of the fields due to the electric current moving continuously in back and forth motion. Radio waves are launched by the antenna and are picked up by a receiver in the cell phone tower ${ }^{2}$. At present, there are 7 billion people of whom 6 billion are mobile users; surprisingly some of these mobile phone users are very young, i.e. less than 5 -year-old ${ }^{3}$. The interaction between the radiations emitted and absorbed by the body can be calculated by SAR (specific absorption rate), which may be defined as the velocity of energy at the point the radiation is absorbed by the human body. Its unit is power by mass of tissue i.e. Watt / kilogram 4 .

There have been unpredictable increasing rates of using mobile phones in recent years. It is one of the fastest launched wireless communication devices among all. The mobile service is now playing a potential role in the advancement of education, health-care delivery and management ${ }^{5}$. But there is another side of the coin which shows its bad effects, such as when the mobile phone is vibrated, it poses harmful effects on the human body. Scientists suggest that if there is long-term exposure of mobile phones, it may produce disturbances within the body 6,7 . When humans are exposed to electromagnetic radiations emitted from mobile phones, the electromagnetic energy can pass through the skin. It is not necessary that the surface layer will always make a barrier against it. This radiation penetrates in the subcellular structures through barriers of the body. Different epidemiological studies have shown that this radiation produces its adverse effect on the closed area of emission and leads to causing brain tumors, however, the mechanism is still unresolved ${ }^{3,8-9}$. Almost $60 \%$ of the human body is made up of water. When the energy of the radio frequency range is absorbed in an aqueous medium, there is the production of chemically reactive species that can collaborate with solutes. This confirms the synthesis of hydrogen atoms and dioxin radical anion from the decomposition of water in the excited state. As all biomolecules exist in aqueous media, any change in the chemistry of water automatically changes the environment of biomolecules. For example, hydroxyl radical chemically interferes with deoxyribose nucleic acid (DNA) and break its strands ${ }^{10}$. Excessive synthesis of free oxygen radicals is known as an oxidative hassle, which may cause oxidation of protein, enzyme denaturation and peroxidation of lipids molecules beneath the plasma membrane internal structure thus resulting in structural and functional disturbances or abnormalities of the cell. Free radicals damage DNA and RNA and increase chances of mutation ${ }^{11}$. A state that the interaction between magnetic surroundings and biological system entail the contribution oxidative stress particularly by the radical duo system. The use of low-level of the electromagnetic field for a minimal time period are not effective to alter the biological structures in human body ${ }^{12}$. In animal models, the electric field increased lipid peroxidation and change in antioxidant level ${ }^{13}$. However, the complaints of sleep disturbances, headache, dizziness, irritability, focused problems, and hypertension is also received from the nearby living persons to mobile base stations but the mechanism is still unknown ${ }^{14}$.

Salivary gland is situated near the ear. The major divisions of salivary gland area parotid gland, submandibular and sublingual glands from where human saliva is released. The major portion of saliva is constituted by water; saliva also has enzymes and proteins. When ear close with a mobile phone, parotid gland is nearest exposed site amongst all glands, hence it is the most affected part while using a mobile phone. The molecules present in saliva are gradually affected due to radiations emitted by mobile phones causing perturbation in their function, either they become reduced or increased in saliva ${ }^{15}$. There is a chance of activation and/or deactivation of hormones, enzymes or some functional proteins produced in that region. The contents present in salivary secretions other than hormones are salivary enzymes like salivary amylase, salivary lipase etc.; antioxidant enzymes like catalase, glutathione peroxidase, superoxide dismutase; and some proteins, e.g. CRP (C-reactive protein) which may be significantly affected by mobile phone radiations. Saliva also has antibacterial agents like IgA, lysozyme, and lectoferrin ${ }^{16,17}$. The physiological action and scavenge capability of antioxidants can be impaired due to the presence of oxidative stress ${ }^{8,13}$. Collectively inherent antioxidants in the immune system can be exclusively disturbed through amplification of oxidative stress caused by electromagnetic fields ${ }^{6}$. Nature has created various biomolecules including glutathione peroxidase, 
superoxide dismutase, catalase, C-reactive protein, uric acid, ascorbic acid, etc. present in the human body as well as saliva ${ }^{18}$. These molecules are affected by heavy use of mobilephones ${ }^{9}$. Among various causes of oxidative stress within the human body, some controversial studies have indicated electromagnetic radiation from cellular phones $^{19}$. The aim of the current study was to find out the relationship between mobile phone use and oxidative markers in saliva. In Pakistan, people are using a range of mobile phones from simple to smartphones. Products of various companies are available in the market. The present study focused only on the duration of usage regardless of the quality of cellular phone to determine oxidative state/stress marker in saliva.

\section{MATERIALS AND METHODS}

The study accomplished local population. Volunteers were either in sex with different age groups. The saliva was collected by following the method of Navazesh ${ }^{20}$. All participants were healthy and heavy user of Global System of Mobile Communication (GSM). A questionnaire was filled with participants. The exclusion criteria of the study were, usage of drugs, smoking, pregnancy, any trauma, headaches, injuries, chronic systematic diseases, and the history of any chemotherapy and radiotherapy.

The volunteer of non-mobile phone user was kept as control. The volunteers of the mobile phone user were further grouped into 3 groups (Table 1).

Table 1. Groups of mobile phone user.

\begin{tabular}{cccc}
\hline Parameter & Group 1 & Group 2 & Group 3 \\
\hline $\begin{array}{c}\text { Calls Per Day } \\
\text { (minutes) }\end{array}$ & $5-10$ & $5-10$ & $10-25$ \\
\hline $\begin{array}{c}\text { Time Spent } \\
\text { On Each Call } \\
\text { (minutes) }\end{array}$ & $5-15$ & $30-60$ & $5-15$ \\
\hline
\end{tabular}

\section{SAMPLE COLLECTION}

Saliva was collected by passive drool method without using any stimuli. The saliva collected in the sterile container between 9 am to $11 \mathrm{am}$. The unstimulated saliva was collected for at least 5 minutes after 60 seconds of intervals. After collection, all samples of saliva were centrifuged at $3500 \mathrm{rpm}$ for 15 minutes to clear all unwanted substance. The supernatant was separated in Eppendorf and stored at $-20^{\circ} \mathrm{C}$ until tests were performed.

\section{BIOCHEMICAL ANALYSIS}

\section{Estimation of Uric Acid}

The assayed was based on enzymatic colorimetric method. The commercially prepared kit was supplied by Randox in which uricase is responsible for the conversion of uric acid into allantoin and hydrogen peroxide, then under the catalytic influence of peroxidase, oxidizes 3,5Dichloro-2-hydroxybenzene sulfonic acid and 4aminophenazone to form a red-violet quinoneimine derivative observe at $520 \mathrm{~nm}$.

\section{Estimation of C-Reactive Protein}

The assay based on the principle of agglutination. The commercially prepared kit was supplied by SBio in which semi-quantitative method was used by preparing the serial dilution of each sample. The test specimen was mix with SBio CRP latex reagent to for the continuation of the reaction. If there was agglutination seen the CRP is $>0.6$ $\mathrm{mg} / \mathrm{dl}$, then performed serial dilution and calculated the results. If there is no agglutination after mixing so the concentration of CRP is less than $0.6 \mathrm{mg} / \mathrm{dl}$.

\section{Estimation of Catalase}

In $0.1 \mathrm{ml}$ of supernatant, the reaction mixture was made by adding up $1 \mathrm{ml}$ of $0.01 \mathrm{M}$ of phosphate buffer ( $\mathrm{pH} 7.0$ ), $0.4 \mathrm{ml}$ of $2 \mathrm{M} \mathrm{H}_{2} \mathrm{O}_{2}$. After the addition of $2 \mathrm{ml}$ dichromateacetic acid reagent ( $5 \%$ potassium dichromate and glacial acetic acid were mixed in a ratio of 1:3). Checked it at 610 $\mathrm{nm}$ and calculate the values by using standard curve $(0.2$ molar-2 molars). The unit expressed as gm/dl 21.

\section{Estimation of Reduced Glutathione (GSH)}

The $2 \%$ trichloro-acetic acid added in $0.5 \mathrm{ml}$ of supernatant. At 3000rpm for 15 minutes the mixture was centrifuged. Then added $0.5 \mathrm{ml}$ of Ellman's reagent and $0.2 \mathrm{M}$ phosphate buffer (pH 8.0). Calculate percent inhibition after checking $412 \mathrm{~nm}$ at absorbance ${ }^{22}$.

\section{Estimation of Superoxide Dismutase (SOD)}

In $0.1 \mathrm{ml}$ of supernatant, $0.15 \mathrm{ml}$ of ice chilled chloroform and $0.75 \mathrm{ml}$ of ethanol mixed together. At $3000 \mathrm{rpm}$ for 15 
minutes place the tube for centrifugation. Added $1.0 \mathrm{ml}$ of $0.1 \mathrm{M}$ of carbonate-bicarbonate buffer $(\mathrm{pH} 10.2)$ and $0.5 \mathrm{ml}$ of EDTA $(0.6 \mathrm{mM})$. The procedure was then continued after the addition of epinephrine $(1.8 \mathrm{~mm})$. At $480 \mathrm{~nm}$ the readings were measured for 3 minutes to calculate percent inhibition ${ }^{23}$.

\section{STATISTICAL ANALYSIS}

Statistical analysis was done on the graph pad (www.graphpad.com), which is a freely available resource. The two tail $P$ value was used to calculate significance $(P<0.05)$.

\section{RESULTS AND DISCUSSION}

In our study Uric acid, Reduced Glutathione (GSH) and Superoxide Dismutase's (SOD), Catalase and CRP were measured. Among these Parameters Uric acid, GSH, SOD was significantly decreased than control as shown in Figure 1. Previous studies show that a significant decrease in antioxidant profile increases the risk of inflammatory diseases of the oral cavity such as gingivitis, periodontitis, and mucositis in individuals utilizing cell phones for longer durations ${ }^{24}$. Reduced Glutathione (GSH), Superoxide Dismutase (SOD) and catalase contribute towards Total Antioxidant Capacity (TAC), that is an integral antioxidant defense mechanism that counteracts with Reactive Oxygen Species (ROS). Saliva is not invasively collected, non-intrusive manner and acts as a first line scavenger of free radical species resulting in minimizing oxidative stress ${ }^{8}$.

The previous study revealed the salivary Uric Acid is considered to be the most important antioxidant molecule in saliva as it contributes to almost $70 \%$ of the salivary TAC. All the three groups in this study demonstrated significantly lower values of uric acid in a contrast to that of the control group, while Group 2 shows a steep decline in salivary Uric acid levels. Thus, the oxidative stress of long-term cell phone usage results in a reduction of salivary Uric Acid and this directly possesses effector salivary antioxidants ${ }^{19}$.

It was stated the significantly reduced capacity of the enzymatic profile of antioxidant with a concurrent rise in lipid peroxidation when exposed to even extremely low frequencies of electromagnetic radiation in Albino Wistar rats $^{13}$. Histochemical changing has been observed in rat's paranoid gland when exposed from $2100 \mathrm{MHz}$ of radiation that was emitted from the $3 G$ mobile phone. These histopathological changes were observed in acinar cells, interstitial space, ductal system, vascular system ${ }^{25}$. These changes influence the rate of antioxidant level in saliva were proved ${ }^{19}$.

So this it can be incurred that saliva is an indicator of oxidative stress when using mobile phones ${ }^{25}$, have demonstrated the antioxidant body clock in rats at the result of electromagnetic exposure ${ }^{26}$.

However, on the other hand, the antioxidant, the short time contact of electromagnetic emission from mobile devices produce none of the significant effects ${ }^{13}$. It was reported experimental data which shows the short-term exposure of electromagnetic radiations may have a deleterious influence on blood serotonin and glutamate levels ${ }^{27}$. The reason for significantly lowered values of uric acid, GSH and SOD was the alteration on the molecular level, the mobile phone emission of electromagnetic radiations may effect on the genetic expression which influences the oxidative stress ${ }^{28}$. The free radical's activity detoxifies by the action of SOD and GSH, the product of SOD is hydrogen superoxide may inhibit SOD activity. In our finding the GSH also decreased, both enzymes (GSH, SOD) show a decrease in their activity may induce noxious metabolic outcome 9 .

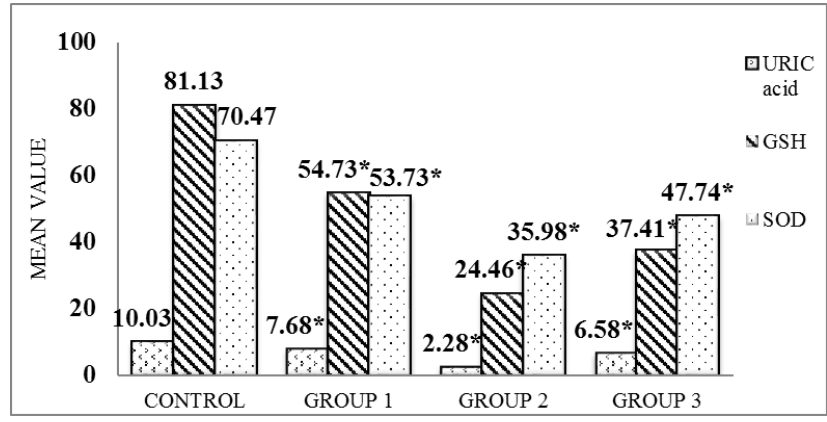

Figure 1. Estimation of Uric acid, GSH, SOD. Results are expressed as mean \pm SEM (standard error of the mean). The value of $n$ for control, group 1, 2 and 3 are 26, 38, 27, and 20 respectively. Every single mean was run in triplicate. $\mathrm{P}(<0.05)$ was calculated by two tail analysis. *Significant when compared with control.

In this study, catalase and CRP was measured, in Figure 2. Both were significantly increased than control which 
shows that there is an activation induced by electromagnetic radiations. In accordance the creation of ROS was scavenged through antioxidants, hence the catalase increases after the exposure of electromagnetic field29. In our study, only C - reactive protein (CRP) was determined through a semi-quantitative method. The relation between the mobile phone user of all three groups and CRP was significantly increased than that of the control group. The levels of CRP are in a linear relationship with the duration of cell phone usage. In addition, the physical activity will increase the value of CRP and other inflammatory markers ${ }^{26}$. It was showed that the erythro-leukemic cell has increased their catalase, cytochrome P450, and nitric oxide synthase action when it is exposed to extremely low-frequency electromagnetic field (ELF-EMF) ${ }^{30}$. The findings of elevated salivary CRP levels in this study are congruent with previous studies indicating the presence of gingival and periodontal inflammation in the absence of plaque and calculus ${ }^{31-33}$.

Our findings suggested that the long-term exposure of mobile phone generate oxidative stress, the reactive oxygen species are formed and the body increases the synthesis of catalase to convert the metabolic product of hydrogen peroxide in water ${ }^{19}$. The increment in C-reactive protein shows an inflammation response, also associated with oxidative stress.

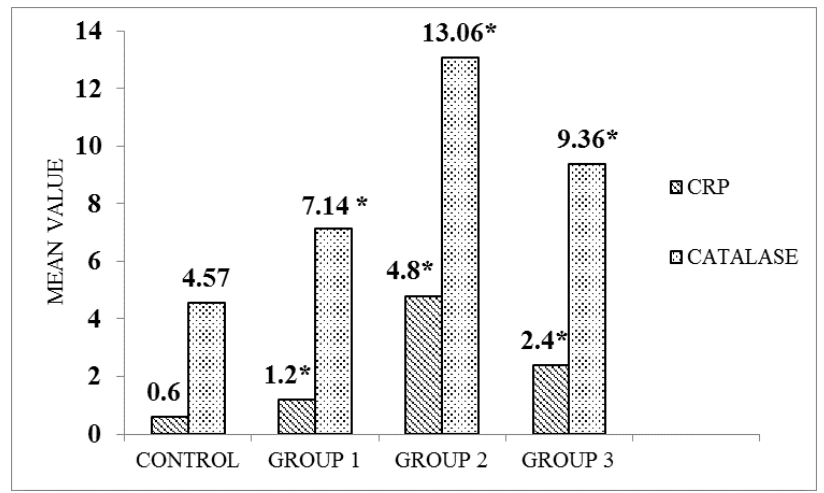

Figure 2. Estimation of CRP and Catalase. Results are expressed as mean \pm SEM (standard error of the mean). The value of $n$ for control, group 1, 2 and 3 are 26, 38, 27, and 20. Every single mean was run in triplicate. $P(<0.05)$ was calculated by two tail analysis. *Significant when compared with control.

Studies of antioxidants that comprise of the salivary TAC are of utmost importance as a significant proportion of oral diseases have established associations with salivary TAC ${ }^{18}$. Imbalances between ROS and TAC in saliva perform a crucial role in causing of diseases and growth of infectious or non-infectious diseases of oral cavity 3,28 . The two most common non-communicable dental diseases namely Dental Caries and Periodontitis are linked with alterations in TAC of saliva ${ }^{34}$, it moderate and severe periodontitis has been associated with low levels of $\mathrm{TAC}^{30}$. Findings of this study implicate that cell phone usage for longer duration leads to significantly reduced levels of salivary antioxidants leading to a reduction in cumulative salivary TAC and this is in congruence with previous studies ${ }^{16,30}$. Reduced salivary TAC increases the susceptibility of the oral cavity to a wide range of oral diseases from periodontitis to premalignant lesions and oral cancer ${ }^{35}$.

\section{CONCLUSION}

The study provides the evidence implicating mobile phone usage and reduction in the antioxidant profile in human beings, as far as the effects of Electromagnetic Radiations on the modification of antioxidant markers. The undesirable things of Electromagnetic Radiations are existed in all three groups. These groups were divided according to the calls per day and the minutes spent on each call. Although, this study shows clear evidence of electromagnetic radiation and the significantly decreased levels of salivary SOD, GSH, Uric acid activity while significantly increased levels of catalase and CRP.

We, therefore, conclude that the influence of radiation emitted by the mobile phone decrease the salivary levels of SOD, GSH and Uric acid. The increased activity of CRP \&catalase may implicate the risk of inflammation and oral pathologies from unabated actions of free radicals.

\section{REFERENCES}

1. Mohammadzadeh N, Safdari R, Rahimi A. Cancer care management through a mobile phone health approach: key considerations. Asian Pac J Cancer Prev. 2013; 14(9):4961-4.

2. AhmadiTameh A, Ahmadi R, Gohari A. Long-Term Exposure to Cell Phone Radiation and Stress. EELS. 2014; 43-5.

3. Khadra KMA, Khalil AM, Samak MA, Aljaberi A. Antioxidant profile of saliva among young men using mobile phones. JJBS. 2014; 7(4):275-80. 
4. Munshi A. Cellular phones: To talk or not to talk. J Can Res Ther. 2011; 7(4):476-7.

5. Ahmed $T$, Lucas $H$, Khan AS, Islam R, Bhuiya A, Iqbal $M$. eHealth and mHealth initiatives in Bangladesh: a scoping study. BMC health services research. 2014; 14:260.

6. Lee B-C, John H-M, Lim J-K, Jeong JH, Baik KY, Nam TJ, et al. Effects of extremely low-frequency magnetic field on the antioxidant defense system in mouse brain: a chemiluminescence study. J PhotochemPhotobio B. 200; 73(1-2):43-8.

7. Preethi $B$, Reshma D, Anand P. Evaluation of flow rate, $\mathrm{pH}$, buffering capacity, calcium, total proteins and total antioxidant capacity levels of saliva in caries free and caries active children: an in vivo study. Indian Journal of Clinical Biochemistry. 2010; 25(4):425-8.

8. Nagler RM, Klein I, Zarzhevsky N, Drigues N, Reznick AZ. Characterization of the differentiated antioxidant profile of human saliva. Free Radic Biol Med. 2001; 32(3):268-77.

9. Shivashankara AR, Joy J, Sunitha V, Rai MP, Rao S, Nambranathayil $S$, et al. Effect of cell phone use on salivary total protein, enzymes and oxidative stress markers in young adults: a pilot study. J Clin Diagn Res. 2015; 9(2): BC19-22.

10. Behari J. Biological responses of mobile phone frequency exposure.Indian J Expo Bio. 2010; 48: 95981.

11. Ray G, Husain SA. Oxidants, antioxidants and carcinogenesis. Indian J Exp Biol. 2002; 40(11):121332.

12. Valberg $P$, Kavet $R$, Rafferty C. Can low-level $50 / 60$ $\mathrm{Hz}$ electric and magnetic fields cause biological effects?.Radiat Res. 1997; 148(1):2-21

13. Akpinar D, Ozturk N, Ozen S, Agar A, Yargicoglu P. The effect of different strengths of extremely lowfrequency electric fields on antioxidant status, lipid peroxidation, and visual evoked potentials. Electromagn Biol and Med. 2012; 31(4):436-48.

14. Singh K, Nagaraj A, Yousuf A, Ganta S, Pareek S, Vishnani $P$. Effect of electromagnetic radiations from mobile phone base stations on general health and salivary function. J Int Soc Prev Community Dent. 2016; 6(1):54-9.

15. Kaufman E, Lamster IB. The diagnostic applications of saliva-a review. Crit Rev Oral Biol Med. 2002; 13(12):197-212.
16. Arbabi-Kalati F, Salimi S, Vaziry-Rabiee A, Noraeei M. Effect of mobile phone usage time on the total antioxidant capacity of saliva and salivary immunoglobulin a. Iran J Public Health. 2014; 43(4):480-4.

17. Mortavazi S, Habib A, Ganj-Karami A, Samimi-Doost R, Pour-Abedi A, Babaie A. Alterations in TSH and thyroid hormones following mobile phone use. Oman Med J. 2009; 24(4):274-8.

18. Battino M, Ferreiro M, Gallardo I, Newman H, Bullon P. The antioxidant capacity of saliva. J Clin Periodontol. 2002; 29(3):189-94.

19. Abu Khadra KM, Khalil AM, Abu Samak M, Aljaberi A. Evaluation of selected biochemical parameters in the saliva of young males using mobile phones. Electromagn Biol Med. 2015; 34(1):72-6.

20. Navazesh M. Methods for collecting saliva. Annals of the New York Academy of Sciences. 1993; 694:72-7.

21. Sinha A. K. Colorimetric assay of catalase. Anal Biochem. 1972; 47(2):389-94.

22. Ellman G.L. Tissue sulfhydryl groups. Arch Biochem and Biophys. 1959; 82(1): 70-7.

23. Misra H.P., Fridovich I. The role of superoxide anion in the autoxidation of epinephrine and a simple assay for superoxide dismutase. Journal of Bio Chem. 1972; 247(10):3170-5.

24. Dodwad R, Betigeri AV, Preeti B. Estimation of total antioxidant capacity levels in saliva of caries-free and caries-active children. Contemp Clin Dent. 2011; 2(1):17-20.

25. Aydogan F, Unlu I, Aydin E, Yumusak N, Devrim E, Samim EE, et al. The effect of $2100 \mathrm{MHz}$ radiofrequency radiation of a $3 \mathrm{G}$ mobile phone on the parotid gland of rats.American journal of otolaryngology. 2015; 36(1):39-46.

26. Cao H, Qin F, Liu X, Wang J, Cao Y, Tong J, et al. Circadian rhythmicity of antioxidant markers in rats exposed to $1.8 \mathrm{GHz}$ radiofrequency fields. Int J Environ Res Public Health. 2015; 12(2):2071-87.

27. Eris A, Kiziltan H, Meral I, Genc H, Trabzon M, Seyithanoglu $\mathrm{H}$, et al. Effect of Short-term $900 \mathrm{MHz}$ low-level electromagnetic radiation exposure on blood serotonin and glutamate levels. Bratisl Lek Listy. 2014; 116(2):101-3.

28. Khalil AM, Abu Khadra KM, Aljaberi AM, Gagaa MH, Issa HS.Assessment of oxidant/antioxidant status in 
the saliva of cell phone users. Electromagn Biol Med. 2014; 33(2):92-7.

29. Patruno A, Tabrez S, Pesce M, Shakil S, Kamal MA, Reale M. Effects of extremely low-frequency electromagnetic field (ELF-EMF) on catalase, cytochrome P450 and nitric oxide synthase in erythroleukemic cells. Life Sci. 2015; 121:117-23.

30. Canakci V, Yildirim A, Canakci CF, Eltas A, Cicek Y, Canakci $\mathrm{H}$. Total antioxidant capacity and antioxidant enzymes in serum, saliva, and gingival crevicular fluid of preeclamptic women with and without periodontal disease. J Periodontol. 2007; 78(8):1602-11.

31. Vogel GL, Carey CM, Chow LC, Tatevossian A. Micro-analysis of plaque fluid from single-site fasted plaque. J Dent Res. 1990;69(6):1316-23.

32. Rankine CAN, Moreno EC, Vogel GL, Margolis HC. Micro-analytical Determination of $\mathrm{pH}$, Calcium, and
Phosphate in Plaque Fluid. J Dent Res. 1985; 64(11):1275-80.

33. Silva-Boghossian CM, Orrico SR, Gonçalves D, Correa FO, Colombo AP. Microbiological changes after periodontal therapy in diabetic patients with inadequate metabolic control. Braz Oral Res. 2018; 28:1-9.

34. Hegde A, Rai K, Padmanabhan V. Total antioxidant capacity of saliva and its relation with early childhood caries and rampant caries. J Clin Pediatr Dent. 2009; 33(3):231-4.

35. Kolanjiappan K, Ramachandran C, Manoharan S. Biochemical changes in tumor tissues of oral cancer patients. Clin Biochem. 2003; 36(1): 61-5. 